\title{
The Impact of Health Consciousness on the Association Between Walking Durations and Mental Health Conditions After a Disaster: a Cross-Sectional Study
}

Yusuke Utsumi ${ }^{1,2}$, Harumi Nemoto ${ }^{3}$, Naoki Nakaya ${ }^{4}$, Tomohiro Nakamura ${ }^{4}$, Naho Tsuchiya ${ }^{4}$, Akira Narita ${ }^{4}$, Mana Kogure ${ }^{4}$, Tomomi Suzuki ${ }^{1}$, Moe Seto ${ }^{1}$, Mitsuaki Katayanagi ${ }^{1}$, Junko Okuyama ${ }^{3}$, Atsushi Sakuma ${ }^{5}$, Nami Honda ${ }^{6}$, Yumi Sugawara ${ }^{7}$, Halley Kaye-Kauderer ${ }^{8}$, Yuta Takahashi ${ }^{1}$, Akemi Kayama ${ }^{2,9}$, Yoshihisa Kakuto ${ }^{2}$, Masahiro Kohzuki ${ }^{10}$, Atsushi Hozawa ${ }^{4}$, Ichiro Tsuji ${ }^{4,7}$ and Hiroaki Tomita ${ }^{1,3,4,5,6^{*}}$ (D)

\begin{abstract}
Background: In communities affected by a disaster, walking can be a feasible form of physical exercise to improve physical and mental health conditions. However, there is limited evidence to support relationships between walking habits and mental health conditions in post-disaster settings. Cross-sectional epidemiological data obtained from a questionnaire survey (conducted in October 2017) of a community affected by the 2011 Great East Japan Earthquake (GEJE) was analyzed to evaluate the relationships.

Methods: Participants included individuals over 20 years of age $(N=718)$ from Shichigahama town in Miyagi prefecture, whose houses were significantly damaged by the GEJE. Their mental health conditions were assessed by the Kessler Psychological Distress Scale (K6), the Center for Epidemiologic Studies Depression Scale (CES-D), and the Impact of Event Scale-Revised (IES-R). Additionally, the questionnaire asked the participants spent duration walking on average and their walking purpose by the following items: (1) longer than 60 min per day, (2) between 30 and 60 min per day, or (3) less than 30 min per day, and whether they walked to maintain healthy living habits (healthconscious walkers) or merely for transportation without considering health consequences (non-health-conscious walkers). These information and mental health indicators were analyzed using analysis of covariance (ANCOVA).

Results: Among the three walking duration groups of health-conscious walkers, there were significant differences in CES-D and K6 scores ( $p=0.01$ and $p=0.04$ ), but not in IES-R scores, considering age, gender, and alcohol drinking habits as covariates. CES-D score was significantly higher among short walkers $(p=0.004)$. Among the three walking duration groups of non-health-conscious walkers, there were significant differences in avoidance symptoms, the subdomain of IES-R $(p=0.01)$, but not in CES-D, K6, and total IES-R scores, considering the variants.

(Continued on next page)
\end{abstract}

\footnotetext{
* Correspondence: htomita@med.tohoku.ac.jp

'Department of Disaster Psychiatry, Graduate School of Medicine, Tohoku

University, 2-1 Seiryo-Machi, Aoba-ku, Sendai 980-8573, Japan

${ }^{3}$ Department of Disaster Psychiatry, International Research Institute of

Disaster Science, Tohoku University, 2-1 Seiryo-Machi, Aoba-ku, Sendai

980-8573, Japan

Full list of author information is available at the end of the article
}

\section{Springer Open}

(c) The Author(s). 2020 Open Access This article is licensed under a Creative Commons Attribution 4.0 International License, which permits use, sharing, adaptation, distribution and reproduction in any medium or format, as long as you give appropriate credit to the original author(s) and the source, provide a link to the Creative Commons licence, and indicate if changes were made. The images or other third party material in this article are included in the article's Creative Commons licence, unless indicated otherwise in a credit line to the material. If material is not included in the article's Creative Commons licence and your intended use is not permitted by statutory regulation or exceeds the permitted use, you will need to obtain permission directly from the copyright holder. To view a copy of this licence, visit http://creativecommons.org/licenses/by/4.0/. 
(Continued from previous page)

Conclusion: Our study suggests that walking durations may positively affect mood, but not PTSR, only when walking is performed with the purpose of maintaining healthy living habits. Walking durations were negatively associated with avoidance symptoms among non-health-conscious walkers in the community affected by the GEJE, indicating that the disaster may have had a long-lasting impact on walking habits.

Keywords: Physical activity, Walking habits, Health consciousness, Motivation, Optimism, Mental health, Depressive symptoms, Posttraumatic stress reaction, Disaster, the Great East Japan Earthquake

\section{Key Points}

- Among the population who walked for health, walking durations were negatively associated with depressive symptoms but not with posttraumatic stress reactions.

- Among the population who walked for other reasons besides health, walking durations were negatively associated with the avoidance symptoms of posttraumatic stress reaction.

- Encouraging walking for health reasons and rearranging the surrounding environment of the communities affected by a disaster may help to improve their mental health conditions.

\section{Background}

On March 11th, 2011, the northeastern coast of Japan was devastated by the magnitude 9.0 Great East Japan Earthquake (GEJE) and the tsunami that followed. Previous studies indicated that a wide range of stressors, such as house damages caused by the disaster, were associated with mental health consequences, including depressive states and posttraumatic stress reactions (PTSR) [1-6].

In ordinary settings, general physical activities [7-16], including walking [17-22], are positively associated with mental health and well-being and negatively associated with depressive symptoms regardless of age and gender. However, the relationship between physical activities and mental health conditions has not been well characterized in post-disaster settings with an exception which surveyed the area affected by the GEJE and found that decreased physical activity was significantly associated with increased levels of depressive states among elderly people aged $\geqq 65[23,24]$. Likewise, evidence suggests that physical activities such as yoga, aerobics, and resistance training have positively effects on people suffering from PTSR. However, due to the limited number of RCTs, it is unclear the optimal frequency, intensity, type, and time (FITT) of physical activity needed to improve the well-being of people with PTSR [25]. Additionally, there is limited research investigating the relationship between physical activity and PTSR in communities affected by disasters.
It is crucial to evaluate the associations between physical activities and PTSR because persistent avoidance of stimuli is one of the major symptoms of PTSR, along with intrusion symptoms, negative alterations in cognition and mood, and alterations in hypervigilance and reactivity [26]. The avoidance may theoretically deter people suffering from PTSR from walking outside in surrounding areas where they anticipate stimuli by seeing signs or landscapes that evoke trauma-related memories.

It is especially important to evaluate associations between walking habits and mental health conditions in a post-disaster setting because walking remains a feasible form of exercise for affected individuals when a disaster damages other exercise facilities within a community. On the other hand, it is noteworthy that people walk not only for the direct purpose of promoting their health but also for the purpose of dealing with daily tasks like business endeavors, shopping, or chores. While the purpose of walking may theoretically impact the effect of walking on health conditions, this purpose has rarely been investigated in previous studies. One study that explored this question looked at the relationship between the purpose of walking and health conditions in adults aged 60-64 years. This study revealed that participation in leisuretime physical activities and walking for pleasure were positively correlated with mental health and well-being, whereas total levels of free-living physical activities were not [27]. In addition, people with PTSD and depressive symptoms may face considerable barriers to engaging in regular physical activity, similar to those with other mental health disorders (for example, a lack of motivation or optimism) [28-30]. Motivation and optimism (positive expectations of the future) may increase an individual's desire to participate in exercise programs and modify their health behaviors, ultimately leading to improved mental health and well-being.

To figure out the above unelucidated questions regarding walking habits and mental health conditions in communities affected by a disaster, the current study aims to investigate the difference in mental health conditions, such as depressive state and PTSR, among people who had long or short durations of daily walking in post-disaster settings, and how they differ among populations who walked primarily with 
or without the purpose of maintaining a good health condition. The study also intended to examine the difference in emotional pain when seeing signs relevant to a disaster among the subgroups with different walking habits.

\section{Methods}

\section{Study Design, Settings, and Participants}

The present study is based on the Shichigahama Health Promotion Project conducted in partnership between Tohoku University and Shichigahama town, located on the coast of Miyagi Prefecture and previously devastated by the GEJE [2-6]. This project was initiated to improve the mental health and well-being of communities living in Shichigahama town. It began with outreach activities for individuals living in evacuation camps immediately after the disaster and later expanded to personal mental health care and mental health promotions, including mental health workshops for people who moved to prefabricated temporary housings. In addition, annual health surveys of the affected population of the town were conducted since 2011, along with follow-up support programs. Among the total residents at the onset of the GEJE (approximately 22,000; current residents, approximately 19,000 ), there were approximately 2800 identified as people whose houses were totally collapsed or majorly damaged based on public evaluations of the damage. The initial health survey was conducted in October 2011, and subsequent annual surveys have been conducted since then.

In this study, cross-sectional analysis was conducted using data obtained through self-administered questionnaires of the 7th survey conducted in 2017 as well as additional questions focused on walking habits and living environments. The questionnaires were sent and collected via the postal service. The inclusion criteria of the survey were all residents who lived in Shichigahama town at the time of onset of the GEJE and whose houses were severely damaged by the GEJE according to the standard for the public disaster-victim certificate. The inclusion criteria of the current study were individuals over 20 years of age who completed questionnaires regarding mental health, well-being, and walking habits. As for the informed consent process, we declared in the cover letter of the survey that we regarded responses to the questionnaire as consent to participate in the study. Participants were informed that they were free not to participate in the study, with absolutely no negative consequences in any way. Also, participants were told that the findings of this study would be published without any identifying personal information. All personal information, including individual names and addresses, were omitted from the data and substituted with unique codes as identification. The anonymized data was subjected to the subsequent analysis. The study protocol was reviewed and approved by the Ethics Committee of Tohoku University Graduate School of Medicine.

The questionnaires were sent to 3 to 6 age (14 subjects, 9 respondents, response rate $=64 \%$ ), elementary school students to junior high school students (124 subjects, 84 respondents, response rate $=68 \%$ ), high school student equivalent (53 subjects, 36 respondents, response rate $=$ $68 \%$ ), 18 to 19 age (46 subjects, 27 respondents, response rate $=59 \%$ ), adults (2489 subjects, 1334 respondents, response rate $=54 \%$, and total (2726 subjects, all of whom fitted the inclusion criteria, and 1490 responded, response rate $=55 \%$ ). Among them, 718 completed all of the questionnaires for mental health conditions, walking habits, and living environment, which were subjected to the subsequent analysis.

\section{Questionnaires}

The questionnaires of Shichigahama Health Promotion Project survey consisted of the following items: clinical and sociodemographic information (age, sex, marital status, education level, and socioeconomic status), lifestyle behaviors (smoking and alcohol drinking habits), social interactions, social capital, and general health conditions (present medical history, body weight, and height). Regarding alcohol drinking habit and smoking drinking habit were asked as follows. The participants were asked, "Do you drink alcohol?" or "Do you smoke?" and select from "yes" or "no" for the question. The questionnaire also requested detailed information related to how participants experienced the earthquake and tsunami, including the subjects' location at the time of onset of the disaster and evacuation routes, damage to their homes, and loss of family members and close acquaintances.

In order to examine mental health and well-being, psychological distress scores ranging from 0 to 24 were assessed using the Japanese version of the Kessler 6-items scale (K6) [31-34]. Psychological distress scores of $\geq 9$ were classified as a distressed condition. The Center for Epidemiologic Studies Depression Scale (CES-D) was administered to all of the participants to evaluate their depressive symptoms. Each of the 20 items on the CES-D was rated on a 4-point scale ranging from 0 to 3 , which referred to how often the respondent experienced depressive symptoms during the past week. The sum of the scores ranged from 0 to 60 , and scores equal to or above the cut-off score of 16 indicated a depressive state [35]. Impact of Event Scale-Revised (IES-R), consisting of 22 items with a 5-point scale (from 0 to 4), was used for evaluating the severity of PTSR during the previous 7 days. The scores equal to or above the cutoff score of 25 suggested the presence of PTSR [36]. The three subcategories of PTSR symptoms were also 
examined using eight items for re-experiencing items, eight items for avoidance, and six items for hyperarousal.

The questionnaire specifically asked how many minutes the subjects spent walking on average by selecting one of the following items: (1) longer than $60 \mathrm{~min}$ per day, (2) between 30 and 60 min per day, or (3) less than 30 min per day, and classified into "long walkers," "moderate walkers," or "short walkers," respectively, in the subsequent analyses. Additional questions were added after the following indication; "We would like to ask your walking habit and living environment. Please select the most appropriate answer for the following statement". Participants were asked to select from "yes" or "no" for the question; "The reason for your daily walking is for your health?". The participants who selected "yes" or "no" were classified as "health-conscious walkers" or "non-health-conscious walkers" in the subsequent analysis. Emotional pain related to observed landscape destruction is likely to be a factor that will impact walking behavior in post-disaster settings. Therefore, participants were asked to select from "Not applicable," "not completely applicable," "Somewhat applicable," and "Applicable," for the statement to describe their condition; "I feel emotional pain to see signs relevant to a disaster or landscape of the sea after the disaster."

\section{Statistical Analyses}

Differences in the distribution of age (equal to/higher than or younger than 65), gender (male or female), number of family members ( 1 to 9 ), residential status (living in the same place as before the GEJE, living in a different place, not due to the disaster, post-disaster publicly funded rental accommodation, houses of relatives or friends, prefabricated post-disaster public housing, newly built houses in the relocated high-land area, newly built houses outside of the relocated high-land area, or others), economic status (extremely difficult, difficult, a little difficult, or fine), alcohol and tobacco consumptions (alcohol drinking habit or non-alcohol drinking habit and smoking habit or non-smoking habit), purpose of walking (health consciousness walkers or non-healthconscious walkers), CES-D score-based depressed state (equal to/greater than or less than the cut-off point of 16), K6 score-based psychological pain (equal to/greater than or less than the cut-off point of 9), IES-R scorebased PTSR (equal to/greater than or less than the cutoff point of 25), and among the three walking duration groups, long walkers, moderate walkers, and short walkers, were examined using a Chi-square test. Mental health indicators (CES-D scores, $\mathrm{K} 6$ scores, and IES-R scores) of all participants, health-conscious walkers, and non-health-conscious walkers were also compared as continuous variables among the three walking duration groups using analysis of covariance (ANCOVA). In addition, as subtests, the $p$ values for walking durations adjusted by age, gender, and alcohol drinking habits were analyzed by multiple logistic regression model, because these factors showed significant differences in the distributions among the three groups in the above Chisquare analysis. Likewise, the differences in emotional pain to see signs relevant to a disaster or landscape of the sea in the living environment after the disaster were examined among the subgroups regarding the walking habits using ANCOVA, using gender, age, and alcohol drinking habits as covariates. All statistical analyses were conducted using EZR version 1.37, and a $p$ value of < 0.05 was considered statistically significant [37].

\section{Results}

\section{Analyses of All Participants}

In the analyses of all participants, distributions of age, gender, and alcohol drinking habits were significantly different among the three walking groups-long walkers (> $60 \mathrm{~min}$ ), moderate walkers $(30-60 \mathrm{~min})$, and short walkers $(<30 \mathrm{~min})(p=0.03, p<0.001$, and $p=0.03$, respectively), and the proportion of elderlies (age $\geqq 65$ ), females, and alcohol drinkers were more substantial among the subgroups who walked shorter. The distribution of the subpopulation who walked primarily with or without the purpose of maintaining good health conditions also significantly differed across all three walking habit groups $(p=$ 0.04 ), and the proportion of health-conscious walkers was more substantial among the subgroups who walked longer. Regarding mental health conditions, the distribution of the subpopulation who suffered from depressive symptoms (CES-D scores $\geqq 16$ ) and PTSR (IES-R scores $\geqq 25$ ) significantly differed among the three walking durations $(p=0.007$ and $p=0.02$, respectively), but psychological pain did not (K6 scores $\geqq 9$ ). The proportion of people suffering from depressive symptoms and PTSR were more substantial among the subgroups who walked shorter. Distributions of the other characteristics examined in the study were not significantly different among the three groups (Table 1). In the comparisons of mental health indicators among the three walking duration groups using ANCOVA showed that there were significant association seen in K6 and IES-R scores $(p=0.02, p$ $=0.02$ ) but not in CES-D scores (Table 2). Regarding K6 and IES-R, scores were affected not only by walking durations but also by age, gender, and alcohol drinking habits.

\section{Health-Conscious Walkers}

Table 3 illustrates the distributions of characteristics of the three walking duration subgroups among the health- 
Table 1 Demographics of the participants

\begin{tabular}{|c|c|c|c|c|c|c|}
\hline & & $\begin{array}{l}\text { Number of participants } \\
\text { in each demographic } \\
\text { category }\end{array}$ & $\begin{array}{l}\text { Number (\%) of } \\
\text { participants } \\
\text { walking } \geqq 60 \\
\text { min/day }\end{array}$ & $\begin{array}{l}\text { Number (\%) of } \\
\text { participants walking } \\
\text { between } 30 \text { and } 60 \\
\text { min/day }\end{array}$ & $\begin{array}{l}\text { Number (\%) } \\
\text { of participants } \\
\text { walking }<30 \\
\text { min/day }\end{array}$ & $p$ value \\
\hline \multicolumn{2}{|l|}{ Total number } & 718 & 232 & 259 & 227 & \\
\hline \multirow[t]{6}{*}{ Age } & $20-29$ & 101 & $41(17.7)$ & $29(11.2)$ & $31(13.7)$ & $0.03^{*}$ \\
\hline & $30-39$ & 108 & $38(16.4)$ & $42(16.2)$ & $28(12.3)$ & \\
\hline & $40-49$ & 144 & $50(21.6)$ & $54(20.8)$ & $40(17.6)$ & \\
\hline & $50-59$ & 155 & $54(23.3)$ & $59(22.8)$ & $42(18.5)$ & \\
\hline & $60-69$ & 123 & 27 (11.6) & $47(18.1)$ & 49 (22.6) & \\
\hline & $70 \leqq$ & 87 & $22(9.5)$ & $28(10.9)$ & $37(16.3)$ & \\
\hline \multirow[t]{2}{*}{ Gender } & Male & 329 & $128(55.2)$ & $119(45.9)$ & $82(36.1)$ & $\begin{array}{l}< \\
0.001^{* *}\end{array}$ \\
\hline & Female & 389 & $104(44.8)$ & $140(54.1)$ & $145(63.9)$ & \\
\hline \multirow{9}{*}{$\begin{array}{l}\text { The number of family } \\
\text { members }\end{array}$} & 1 & 39 & $9(3.9)$ & $14(5.4)$ & $16(7.0)$ & 0.57 \\
\hline & 2 & 126 & $33(14.2)$ & $47(18.1)$ & $46(20.3)$ & \\
\hline & 3 & 183 & $61(26.3)$ & 69 (26.6) & $53(23.3)$ & \\
\hline & 4 & 123 & $48(20.7)$ & 36 (13.9) & 39 (17.2) & \\
\hline & 5 & 91 & $33(14.2)$ & $31(12.0)$ & $27(11.9)$ & \\
\hline & 6 & 93 & $28(12.1)$ & $36(13.9)$ & $29(12.8)$ & \\
\hline & 7 & 37 & $10(4.3)$ & $17(6.6)$ & $10(4.4)$ & \\
\hline & 8 & 10 & $4(1.7)$ & $4(1.5)$ & $2(0.9)$ & \\
\hline & 9 & 5 & $3(1.3)$ & $2(0.8)$ & $0(0.0)$ & \\
\hline \multirow[t]{8}{*}{ Residential condition } & $\begin{array}{l}\text { Living in the same place as before } \\
\text { the GEJE }\end{array}$ & 169 & $62(26.7)$ & $56(21.6)$ & $51(22.5)$ & 0.51 \\
\hline & $\begin{array}{l}\text { Living in a different place not due } \\
\text { to the disaster }\end{array}$ & 21 & $6(2.6)$ & $7(2.7)$ & $8(3.5)$ & \\
\hline & $\begin{array}{l}\text { Post-disaster publicly funded rental } \\
\text { accommodation }\end{array}$ & 5 & $1(0.4)$ & $3(1.2)$ & $1(0.4)$ & \\
\hline & Houses of relatives or friends & 30 & $7(3.0)$ & $14(5.4)$ & $9(4.0)$ & \\
\hline & $\begin{array}{l}\text { Prefabricated post-disaster public } \\
\text { housing }\end{array}$ & 74 & $24(10.3)$ & $24(9.3)$ & $26(11.5)$ & \\
\hline & $\begin{array}{l}\text { Newly built houses in the relocated } \\
\text { high-land area }\end{array}$ & 171 & $62(26.7)$ & $61(23.6)$ & $48(21.1)$ & \\
\hline & $\begin{array}{l}\text { Newly built houses outside of the } \\
\text { relocated high-land area }\end{array}$ & 175 & $42(18.1)$ & $71(27.4)$ & $62(27.3)$ & \\
\hline & Others & 62 & $23(9.9)$ & $20(7.7)$ & $19(8.4)$ & \\
\hline \multirow{4}{*}{$\begin{array}{l}\text { Perceived economic } \\
\text { status }\end{array}$} & Extremely difficult & 42 & $19(8.2)$ & $14(5.4)$ & $9(4.0)$ & 0.41 \\
\hline & Difficult & 130 & $46(19.8)$ & $41(15.8)$ & $43(18.9)$ & \\
\hline & A little difficult & 215 & $65(28.0)$ & $77(29.7)$ & $73(32.2)$ & \\
\hline & Fine & 328 & $101(43.5)$ & $125(48.3)$ & $102(44.9)$ & \\
\hline \multirow[t]{2}{*}{ Alcohol drinking habits } & Drinking & 273 & $98(42.2)$ & $105(40.5)$ & $70(30.8)$ & $0.03^{*}$ \\
\hline & Non-drinking & 397 & $120(51.7)$ & $136(52.5)$ & $141(62.1)$ & \\
\hline \multirow[t]{2}{*}{ Smoking habits } & Smoking & 138 & $50(21.6)$ & $46(17.8)$ & $42(18.5)$ & 0.52 \\
\hline & Non-smoking & 535 & $167(72.0)$ & $197(76.1)$ & $171(75.3)$ & \\
\hline \multirow{2}{*}{$\begin{array}{l}\text { Walk with health } \\
\text { consciousness }\end{array}$} & Yes & 366 & $113(48.7)$ & $148(57.1)$ & $105(46.3)$ & $0.04^{*}$ \\
\hline & No & 352 & $119(51.3)$ & $111(42.9)$ & $122(53.7)$ & \\
\hline
\end{tabular}


Table 1 Demographics of the participants (Continued)

\begin{tabular}{|c|c|c|c|c|c|c|}
\hline & & $\begin{array}{l}\text { Number of participants } \\
\text { in each demographic } \\
\text { category }\end{array}$ & $\begin{array}{l}\text { Number (\%) of } \\
\text { participants } \\
\text { walking } \geqq 60 \\
\text { min/day }\end{array}$ & $\begin{array}{l}\text { Number (\%) of } \\
\text { participants walking } \\
\text { between } 30 \text { and } 60 \\
\text { min/day }\end{array}$ & $\begin{array}{l}\text { Number (\%) } \\
\text { of participants } \\
\text { walking < } 30 \\
\text { min/day }\end{array}$ & $p$ value \\
\hline \multirow[t]{2}{*}{ CES-D } & $<16$ & 532 & $180(77.6)$ & 201 (77.6) & $151(66.5)$ & $0.007^{*}$ \\
\hline & $\geqq 16$ & 186 & $52(22.4)$ & $58(22.4)$ & 76 (33.5) & \\
\hline \multirow[t]{2}{*}{ K6 } & $<9$ & 630 & 206 (88.8) & $233(90.0)$ & $191(84.1)$ & 0.13 \\
\hline & $\geqq 9$ & 88 & $26(11.2)$ & $26(10.0)$ & 36 (15.9) & \\
\hline \multirow[t]{2}{*}{ IES-R } & $<25$ & 576 & 191 (82.3) & 217 (83.8) & $168(74.0)$ & $0.02^{*}$ \\
\hline & $\geqq 25$ & 142 & $41(17.7)$ & $42(16.2)$ & $59(26.0)$ & \\
\hline
\end{tabular}

Distribution of the participants regarding age groups $(20-29,30-39,40-49,50-59,60-69,70 \leqq)$, gender, number of family members, residential status at the time of the survey [living in the same place as before the Great East Japan Earthquake (GEJE), living in a different place with reasons other than the consequence of the GEJE, post-disaster publicly funded rental accommodation, houses of relatives or friends, prefabricated post-disaster public housing, newly built houses in the relocated high-land area, newly built houses outside of the relocated high-land area, others], economic states (extremely difficult, difficult, a little difficult, fine), alcohol consumption (drinking, non-drinking), smoking status (smoking, non-smoking), walking with health consciousness (yes, no), the Center for Epidemiologic Studies Depression Scale (CES-D; non-depressive: $<16$, depressive: $\geqq 16$ ), the Kessler Psychological Distress Scale (K6; non-distressed: <9, distressed: $\geqq 9$ ), and the Impact of Event Scale-Revised (IES-R; non-PTSR $<25$, PTSR $\geqq 25$ ). The distributions of the above parameters were shown for each walking durations subgroup ( $\geqq$ $60 \mathrm{~min} /$ day, between 30 and $60 \mathrm{~min} /$ day, $<30 \mathrm{~min} /$ day). Differences in the distributions of each parameter among the three walking duration subgroups were evaluated using the Chi-square test

Significance levels: ${ }^{*} p<0.05,{ }^{* *} p<0.01$

conscious walkers $(N=366)$. The distributions in proportions of each gender and depressed subgroup significantly differed among the three groups $(p=0.01$ and $p$ $=0.007$, respectively), and the proportion of females and depressed people were more substantial in the subgroups who walked shorter. The distributions of the other characteristics were not significantly different among the three-walking duration groups. In the comparisons of mental health indicators among the three walking duration groups, ANCOVA showed that there were significant differences in CES-D and K6 scores ( $p=$ 0.01 and $p=0.04$ ) but not in IES-R scores (Table 4). In addition, as subtest, $p$ values based on the logistic regression model using CES-D and K6 scores as objective variable and walking durations, age, gender, and alcohol drinking habits as an independent variable were analyzed by Bonferroni multiple comparison corrections. CES-D score was significantly different between long and short walkers $(p=0.004)$. K6 score was not significantly different among the three walking duration groups. Also, there were no significant differences in total IES-R scores and subdomain scores of IES-R among the three walking duration groups (Table 5).

\section{Non-Health-Conscious Walkers}

Table 6 illustrates the distributions of characteristics of the three walking duration subgroups among the nonhealth-conscious walkers $(N=352)$. The distributions in proportions of subgroups regarding age, gender, and alcohol drinking habits significantly differed among the three walking duration groups $(p=0.03, p=0.007$, and $p=0.04$, respectively), and the proportion of elderlies, female, and alcohol drinkers were more substantial among the subgroup with shorter walking durations. In the comparisons of mental health indicators among the three walking duration groups using ANCOVA showed that there were no significant differences in CES-D, K6, and IES-R scores (Table 7). In comparisons of IES-R subdomain scores, there were significant differences in avoidance symptoms $(p=0.01)$, but not in reexperiencing and hyperarousal symptoms, among the three walking duration groups of non-health-conscious walkers (Table 8). In addition, the logistic regression analysis was done using avoidance symptoms as objective variable and walking durations, age, gender, and alcohol drinking habits as an independent variable followed by the Bonferroni multiple comparison correction. Avoidance symptoms were significantly different between moderate and short walkers $(p=0.002)$.

The levels of emotional pain when seeing signs relevant to a disaster or landscape of the sea in the living environment after the disaster were also compared using ANCOVA. There was no significant difference in the level of emotional pain among the three walking duration groups (Table 9).

\section{Discussion}

The current study indicated a significant negative association between walking durations and depressive symptoms in post-disaster settings, which endorsed the positive effect of walking on mental health conditions seen in previous studies conducted in ordinary settings [16-22]. Multi-level meta-analyses have shown that walking, as well as other physical activities, is positively associated with mental health [16], and several interventions that encourage moderate levels of walking or increased physical activities have been shown to reduce depressive symptoms [17-19]. A national study of young 
Table 2 The results of ANCOVA to assess the influence of walking durations and covariate factors on the mental health indicators among total participants

\begin{tabular}{llll}
\hline Factor & Sum Sq & Df & $F$ value \\
\hline CES-D & & & 3.41 \\
Age & 1161 & 5 & 0.21 \\
Gender & 14 & 1 & 0.30 \\
Alcohol drinking habits & 20 & 1 & 2.26 \\
Walking durations & 308 & 2 & 4.90 \\
(interaction) Alcohol drinking habits:gender & 334 & 1 & 0.65 \\
K6 & & 2.01 & 0.58 \\
Age & 172 & 0.05 \\
Gender & 0.8 & 5 & 0.66 \\
Alcohol drinking habits & 11 & 1 & 3.89 \\
Walking durations & 133 & 1 & 2.39 \\
(interaction) Age:gender:walking durations & 410 & 2 & $0.03^{*}$ \\
IES-R & & 10 & 0.08 \\
Age & 3464 & & 0.83 \\
Gender & 44 & 5 & 3.77 \\
Alcohol drinking habits & 109 & 1 & 0.42 \\
Walking durations & 1497 & 1 & $0.02^{*}$ \\
(interaction) Age:gender & 2383 & 2 & $0.009^{* *}$ \\
Alcohol drinking habits:walking durations & 1165 & 5 & 0.59 \\
\hline
\end{tabular}

The table shows the results of the analyses of covariance (ANCOVA) to assess the influence of walking durations, as well as age, gender, and alcohol drinking habits as covariate factors, on the mental health indicators: the Center for Epidemiologic Studies Depression Scale (CES-D), the Kessler Psychological Distress Scale (K6), and the Impact of Event Scale-Revised (IES-R) among total participants

Sum Sq sum of squares, Df degrees of freedom, Pr probability

Significance levels: ${ }^{*} p<0.05,{ }^{* *} p<0.01$

adults revealed that taking more than 7500 steps per day was associated with fewer depressive symptoms [20].

However, these prior studies have rarely differentiated between subjects who walked for health-conscious reasons versus those who walked for other purposes. This question is crucial to explore as the intention behind walking may impact the overall association between walking and improvement of mental health conditions. The current study provided evidence to suggest that only when people walk with a health-conscious mindset can walking have positively affected to improving their depressive symptoms. There was a similar study based on adults aged 60-64 years old showing that leisure-time physical activities and walking for pleasure were positively correlated with good mental health conditions, whereas total levels of free-living physical activities were not [27]. The previous study differs from the current investigation in several crucial regards. Whereas the previous study investigates merely the elderly population, subjects of the current study had a more extensive range of ages, and whereas target physical activities of the previous study included a wide range of activities, the current study focused solely on walking. Also, whereas the previous study classified the purpose of activities and walking into either for pleasure or not, the current study classified the purpose of walking into either they walked for maintaining good health condition or not. The two purposes of walking, for pleasure and health, may not be mutually exclusive but rather may overlap in many cases, and walking with either or both of the purposes may be associated with good mental health conditions.

Another interesting study investigated the impact of the placebo effect on one's perceived impact of physical activity on overall health. More specifically, it illustrated that individuals who were told that their daily work was a good source of exercise (cleaning hotel rooms) perceived themselves to be getting significantly more exercise than before they were informed of this exercise benefit. As a result, compared with the control group, the informed group later showed a decrease in weight, blood pressure, body fat, waist-to-hip ratio, and body mass index [38]. This result suggests that placebo effects can significantly influence physical health outcomes. However, it is also possible that participants with these mindsets have changed the quality and quantity of their engaged physical activity by altering the exercise frequency, pace (intensity, time), and manner of their physical movements (type) [25]. 
Table 3 Demographics of health-conscious walkers

\begin{tabular}{|c|c|c|c|c|c|c|}
\hline & & $\begin{array}{l}\text { Number of participants } \\
\text { in each demographic } \\
\text { category }\end{array}$ & $\begin{array}{l}\text { Number (\%) of } \\
\text { participants } \\
\text { walking } \geqq 60 \mathrm{~min} / \\
\text { day }\end{array}$ & $\begin{array}{l}\text { Number (\%) of } \\
\text { participants walking } \\
\text { between } 30 \text { and } 60 \\
\text { min/day }\end{array}$ & $\begin{array}{l}\text { Number (\%) of } \\
\text { participants walking } \\
<30 \mathrm{~min} / \text { day }\end{array}$ & $p$ value \\
\hline \multicolumn{2}{|l|}{ Total Number } & 366 & 113 & 148 & 105 & \\
\hline \multirow[t]{6}{*}{ Age } & $20-29$ & 31 & $12(10.6)$ & $10(6.8)$ & $9(8.6)$ & 0.25 \\
\hline & $30-39$ & 43 & $16(14.2)$ & 19 (12.8) & $8(7.6)$ & \\
\hline & $40-49$ & 60 & $22(19.5)$ & $21(14.2)$ & $17(16.2)$ & \\
\hline & $50-59$ & 92 & $32(28.3)$ & $37(25.0)$ & $23(21.9)$ & \\
\hline & $60-69$ & 84 & 15 (13.3) & $39(26.4)$ & $30(28.6)$ & \\
\hline & $70 \leqq$ & 56 & $16(14.2)$ & $22(14.9)$ & $18(17.1)$ & \\
\hline \multirow[t]{2}{*}{ Gender } & Male & 165 & $59(52.2)$ & $71(48.0)$ & 35 (33.3) & $0.01^{*}$ \\
\hline & Female & 201 & $54(47.8)$ & 77 (52.0) & $70(66.7)$ & \\
\hline \multirow{9}{*}{$\begin{array}{l}\text { The number of } \\
\text { family members }\end{array}$} & 1 & 21 & $5(4.4)$ & $8(5.4)$ & $8(7.6)$ & 0.59 \\
\hline & 2 & 75 & $18(15.9)$ & $33(22.3)$ & $24(22.9)$ & \\
\hline & 3 & 87 & $29(25.7)$ & $38(25.7)$ & $20(19.0)$ & \\
\hline & 4 & 56 & $17(15.0)$ & $22(14.9)$ & $17(16.2)$ & \\
\hline & 5 & 52 & $22(19.5)$ & $15(10.1)$ & $15(14.3)$ & \\
\hline & 6 & 47 & $13(11.5)$ & 19 (12.8) & $15(14.3)$ & \\
\hline & 7 & 16 & $5(4.4)$ & $7(4.7)$ & $4(3.8)$ & \\
\hline & 8 & 7 & $1(0.9)$ & $4(2.7)$ & $2(1.9)$ & \\
\hline & 9 & 2 & $2(1.8)$ & $0(0.0)$ & $0(0.0)$ & \\
\hline \multirow[t]{8}{*}{$\begin{array}{l}\text { Residential } \\
\text { condition }\end{array}$} & $\begin{array}{l}\text { Living in the same place as } \\
\text { before the GEJE }\end{array}$ & 89 & $33(29.2)$ & 35 (23.6) & $21(20.0)$ & 0.27 \\
\hline & $\begin{array}{l}\text { Living in a different place not } \\
\text { due to the disaster }\end{array}$ & 7 & $3(2.7)$ & $0(0.0)$ & $4(3.8)$ & \\
\hline & $\begin{array}{l}\text { Post-disaster publicly funded } \\
\text { rental accommodation }\end{array}$ & 2 & $0(0.0)$ & $2(1.4)$ & $0(0.0)$ & \\
\hline & Houses of relatives or friends & 14 & $3(2.7)$ & $7(4.7)$ & $4(3.8)$ & \\
\hline & $\begin{array}{l}\text { Prefabricated post-disaster public } \\
\text { housing }\end{array}$ & 35 & $7(6.2)$ & $14(9.5)$ & $14(13.3)$ & \\
\hline & $\begin{array}{l}\text { Newly built houses in the } \\
\text { relocated high-land area }\end{array}$ & 91 & $32(28.3)$ & $34(23.0)$ & $25(23.8)$ & \\
\hline & $\begin{array}{l}\text { Newly built houses outside of } \\
\text { the relocated high-land area }\end{array}$ & 95 & $24(21.2)$ & $44(29.7)$ & $27(25.7)$ & \\
\hline & Others & 29 & $9(8.0)$ & $10(6.8)$ & $10(9.5)$ & \\
\hline \multirow{4}{*}{$\begin{array}{l}\text { Perceived } \\
\text { economic status }\end{array}$} & Extremely difficult & 20 & $7(6.2)$ & $7(4.7)$ & $6(5.7)$ & 0.98 \\
\hline & Difficult & 59 & 19 (16.8) & $23(15.5)$ & $17(16.2)$ & \\
\hline & A little difficult & 106 & $29(25.7)$ & $45(30.4)$ & $32(30.5)$ & \\
\hline & Fine & 179 & $58(51.3)$ & $71(48.0)$ & $50(47.6)$ & \\
\hline \multirow{2}{*}{$\begin{array}{l}\text { Alcohol drinking } \\
\text { habits }\end{array}$} & Drinking & 140 & $45(39.8)$ & $61(41.2)$ & $34(32.4)$ & 0.45 \\
\hline & Non-drinking & 190 & $58(51.3)$ & $74(50.0)$ & $58(55.2)$ & \\
\hline \multirow[t]{2}{*}{ Smoking habits } & Smoking & 55 & $18(15.9)$ & $21(14.2)$ & $16(15.2)$ & 0.93 \\
\hline & Non-smoking & 290 & $89(78.8)$ & $118(79.7)$ & $83(79.0)$ & \\
\hline \multirow[t]{2}{*}{ CES-D } & $<16$ & 279 & $96(85.0)$ & $113(76.4)$ & $70(66.7)$ & $0.007^{* *}$ \\
\hline & $\geqq 16$ & 87 & $17(15.0)$ & 35 (23.6) & 35 (33.3) & \\
\hline
\end{tabular}


Table 3 Demographics of health-conscious walkers (Continued)

\begin{tabular}{|c|c|c|c|c|c|c|}
\hline & & $\begin{array}{l}\text { Number of participants } \\
\text { in each demographic } \\
\text { category }\end{array}$ & $\begin{array}{l}\text { Number (\%) of } \\
\text { participants } \\
\text { walking } \geqq 60 \mathrm{~min} / \\
\text { day }\end{array}$ & $\begin{array}{l}\text { Number (\%) of } \\
\text { participants walking } \\
\text { between } 30 \text { and } 60 \\
\text { min/day }\end{array}$ & $\begin{array}{l}\text { Number (\%) of } \\
\text { participants walking } \\
<30 \text { min/day }\end{array}$ & $p$ value \\
\hline \multirow[t]{2}{*}{ K6 } & $<9$ & 328 & $106(93.8)$ & 133 (89.9) & 89 (84.8) & 0.09 \\
\hline & $\geqq 9$ & 38 & $7(6.2)$ & $15(10.1)$ & $16(15.2)$ & \\
\hline \multirow[t]{2}{*}{ IES-R } & $<25$ & 294 & $96(85.0)$ & $120(81.1)$ & 78 (74.3) & 0.14 \\
\hline & $\geqq 25$ & 72 & $17(15.0)$ & 28 (18.9) & $27(25.7)$ & \\
\hline
\end{tabular}

Distribution of walker with health-conscious group regarding age groups $(20-29,30-39,40-49,50-59,60-69, \leqq 70)$, gender, the number of family members, residential status at the time of the survey [living in the same place as before the Great East Japan Earthquake (GEJE), living in a different place with reasons other than the consequence of the GEJE, post-disaster publicly funded rental accommodation, houses of relatives or friends, prefabricated post-disaster public housing, newly built houses in the relocated high-land area, newly built houses outside of the relocated high-land area, others], economic states (extremely difficult, difficult, a little difficult, fine), alcohol consumption (drinking, non-drinking), smoking status (smoking, non-smoking), the Center for Epidemiologic Studies Depression Scale (CES-D; non-depressive: $<16$, depressive: $\geq 16)$, the Kessler Psychological Distress Scale (K6; non-distressed: < 9, distressed: $\geq 9$ ), and the Impact of Event Scale-Revised (IES-R; non-PTSR $<25$, PTSR $\geqq 25$ ). The distributions of the above parameters were shown for each walking durations subgroup ( $\geqq 60$ min/ day, between 30 and $60 \mathrm{~min} /$ day, $<30 \mathrm{~min} /$ day). Differences in the distributions of each parameter among the three walking duration subgroups were evaluated using the Chi-square test

Significance levels: ${ }^{*} p<0.05,{ }^{* *} p<0.01$

Another study examined the physical and psychological consequences of undergraduate students who were placed in three different exercise groups: no aerobic exercise, aerobic exercise only, or aerobic exercise with deliberate manipulation of their expectations (i.e.,

Table 4 The results of ANCOVA to assess the influence of walking durations and covariate factors on the mental health indicators among health-conscious walkers

\begin{tabular}{lllll}
\hline & $\begin{array}{c}\text { Sum } \\
\text { Sq }\end{array}$ & Df & $F$ value & $\operatorname{Pr}(>F)$ \\
\hline CES-D & & & & \\
Age & 534 & 5 & 1.74 & 0.1 \\
Gender & 7 & 1 & 0.12 & 0.73 \\
Alcohol drinking habits & 19 & 1 & 0.30 & 0.58 \\
Walking durations & 553 & 2 & 4.49 & $0.01^{*}$ \\
K6 & & & & \\
Age & 111 & 5 & 1.54 & 0.18 \\
Gender & 5 & 1 & 0.32 & 0.57 \\
Alcohol drinking habits & 4 & 1 & 0.26 & 0.61 \\
Walking durations & 90 & 2 & 3.14 & $0.04^{*}$ \\
(interaction) Age:alcohol drinking & 172 & 5 & 2.39 & $0.04^{*}$ \\
habits & & & & \\
IES-R & & & & \\
Age & 1943 & 5 & 2.48 & $0.03^{*}$ \\
Gender & 5 & 1 & 0.03 & 0.86 \\
Alcohol drinking habits & 361 & 1 & 2.31 & 0.13 \\
Walking durations & 614 & 2 & 1.96 & 0.14 \\
(interaction) Age:walking durations & 3090 & 10 & 1.98 & $0.04^{*}$ \\
\hline
\end{tabular}

The table shows the results of the analyses of covariance (ANCOVA) to assess the influence of walking durations, as well as age, gender, and alcohol drinking habits as covariate factors, on the mental health indicators: the Center for Epidemiologic Studies Depression Scale (CES-D), the Kessler Psychological Distress Scale (K6), and the Impact of Event Scale-Revised (IES-R) among health-conscious walkers

Sum Sq sum of squares, Df degrees of freedom, $\operatorname{Pr}$ probability

Significance levels: ${ }^{*} p<0.05,{ }^{* *} p<0.01$ told of benefits) [39]. Ultimately, they found that individuals placed in both the aerobic exercise-only group and the aerobic exercise with deliberate manipulation of expectations group showed significant improvements in cardiovascular fitness. Additionally, the aerobic exercise with the manipulation of expectations group was found to have significant improvements in well-being and self-

Table 5 The results of ANCOVA to assess the influence of walking durations and covariate factors on the IES-R subdomain indicators among health-conscious walkers

\begin{tabular}{lllll}
\hline Factor & Sum Sq & Df & F value & $\operatorname{Pr}(>\mathrm{F})$ \\
\hline Re-experiencing & 338 & 5 & 2.86 & $0.02^{*}$ \\
Age & 1.3 & 1 & 0.05 & 0.82 \\
Gender & 54 & 1 & 2.30 & 0.13 \\
Alcohol drinking habits & 91 & 2 & 1.91 & 0.15 \\
Walking durations & 528 & 5 & 2.23 & $0.02^{*}$ \\
(interaction) Age:walking durations & & & & \\
Avoidance & 386 & 5 & 3.00 & $0.01^{*}$ \\
Age & 10 & 1 & 0.37 & 0.54 \\
Gender & 46 & 1 & 1.80 & 0.18 \\
Alcohol drinking habits & 83 & 2 & 1.60 & 0.2 \\
Walking durations & & & & \\
Hyperarousal & 75 & 5 & 1.14 & 0.34 \\
Age & 4 & 1 & 0.29 & 0.59 \\
Gender & 23 & 1 & 1.76 & 0.19 \\
Alcohol drinking habits & 40 & 2 & 1.53 & 0.22 \\
Walking durations & 250 & 10 & 1.90 & $0.04^{*}$ \\
(interaction) Age:walking durations & & &
\end{tabular}

The table shows the results of the analyses of covariance (ANCOVA) to assess the influence of walking durations, as well as age, gender, and alcohol drinking habits as covariate factors, on the Impact of Event Scale-Revised (IESR) subdomain indicators: re-experiencing, avoidance, and hyperarousal among health-conscious walkers

Sum Sq sum of squares, Df degrees of freedom, $\operatorname{Pr}$ probability

Significance levels: ${ }^{*} p<0.05,{ }^{* *} p<0.01$ 
Table 6 Demographics of non-health-conscious walkers

\begin{tabular}{|c|c|c|c|c|c|c|}
\hline & & $\begin{array}{l}\text { Number of participants } \\
\text { in each demographic } \\
\text { category }\end{array}$ & $\begin{array}{l}\text { Number }(\%) \text { of } \\
\text { participants } \\
\text { walking } \geqq 60 \\
\text { min/day }\end{array}$ & $\begin{array}{l}\text { Number (\%) of } \\
\text { participants walking } \\
\text { between } 30 \text { and } \\
60 \text { min/day }\end{array}$ & $\begin{array}{l}\text { Number }(\%) \text { of } \\
\text { participants } \\
\text { walking }<30 \\
\text { min/day }\end{array}$ & $p$ value \\
\hline Total number & & 352 & 119 & 111 & 122 & \\
\hline \multirow[t]{6}{*}{ Age } & $20-29$ & 70 & $29(24.4)$ & $19(17.1)$ & $22(18.0)$ & $0.03^{*}$ \\
\hline & $30-39$ & 65 & $22(18.5)$ & $23(20.7)$ & $20(16.4)$ & \\
\hline & $40-49$ & 84 & $28(23.5)$ & $33(29.7)$ & $23(18.9)$ & \\
\hline & $50-59$ & 63 & $22(18.5)$ & $22(19.8)$ & 19 (15.6) & \\
\hline & $60-69$ & 39 & $12(10.1)$ & $8(7.2)$ & 19 (15.6) & \\
\hline & $70 \leqq$ & 31 & $6(5.0)$ & $6(5.4)$ & 19 (15.6) & \\
\hline \multirow[t]{2}{*}{ Gender } & Male & 164 & $69(58.0)$ & $48(43.2)$ & 47 (38.5) & $0.007^{* *}$ \\
\hline & Female & 188 & $50(42.0)$ & $63(56.8)$ & $75(61.5)$ & \\
\hline \multirow{9}{*}{$\begin{array}{l}\text { The number of } \\
\text { family members }\end{array}$} & 1 & 18 & $4(3.4)$ & $6(5.4)$ & $8(6.6)$ & 0.17 \\
\hline & 2 & 51 & 15 (12.6) & 14 (12.6) & $22(18.0)$ & \\
\hline & 3 & 96 & 32 (26.9) & 31 (27.9) & $33(27.0)$ & \\
\hline & 4 & 67 & $31(26.1)$ & $14(12.6)$ & $22(18.0)$ & \\
\hline & 5 & 39 & $11(9.2)$ & $16(14.4)$ & $12(9.8)$ & \\
\hline & 6 & 46 & 15 (12.6) & $17(15.3)$ & $14(11.5)$ & \\
\hline & 7 & 21 & $5(4.2)$ & $10(9.0)$ & $6(4.9)$ & \\
\hline & 8 & 3 & $3(2.5)$ & $0(0.0)$ & $0(0.0)$ & \\
\hline & 9 & 3 & $1(0.8)$ & $2(1.8)$ & $0(0.0)$ & \\
\hline \multirow[t]{8}{*}{$\begin{array}{l}\text { Residential } \\
\text { condition }\end{array}$} & $\begin{array}{l}\text { Living in the same place as before the } \\
\text { GEJE }\end{array}$ & 80 & $29(24.4)$ & $21(18.9)$ & $30(24.6)$ & 0.47 \\
\hline & $\begin{array}{l}\text { Living in a different place not due to } \\
\text { the disaster }\end{array}$ & 14 & $3(2.5)$ & $7(6.3)$ & $4(3.3)$ & \\
\hline & $\begin{array}{l}\text { Post-disaster publicly funded rental } \\
\text { accommodation }\end{array}$ & 3 & $1(0.8)$ & $1(0.9)$ & $1(0.8)$ & \\
\hline & Houses of relatives or friends & 16 & $4(3.4)$ & $7(6.3)$ & $5(4.1)$ & \\
\hline & $\begin{array}{l}\text { Prefabricated post-disaster public } \\
\text { housing }\end{array}$ & 39 & $17(14.3)$ & $10(9.0)$ & $12(9.8)$ & \\
\hline & $\begin{array}{l}\text { Newly built houses in the relocated } \\
\text { high-land area }\end{array}$ & 80 & $30(25.2)$ & $27(24.3)$ & $23(18.9)$ & \\
\hline & $\begin{array}{l}\text { Newly built houses outside of the } \\
\text { relocated high-land area }\end{array}$ & 80 & $18(15.1)$ & $27(24.3)$ & $35(28.7)$ & \\
\hline & Others & 33 & $14(11.8)$ & $10(9.0)$ & $9(7.4)$ & \\
\hline \multirow{4}{*}{$\begin{array}{l}\text { Perceived economic } \\
\text { status }\end{array}$} & Extremely difficult & 22 & $12(10.1)$ & $7(6.3)$ & $3(2.5)$ & 0.15 \\
\hline & Difficult & 71 & $27(22.7)$ & $18(16.2)$ & $26(21.3)$ & \\
\hline & A little difficult & 109 & $36(30.3)$ & $32(28.8)$ & 41 (33.6) & \\
\hline & Fine & 149 & $43(36.1)$ & $54(48.6)$ & $52(42.6)$ & \\
\hline \multirow{2}{*}{$\begin{array}{l}\text { Alcohol drinking } \\
\text { habits }\end{array}$} & Drinking & 133 & $53(44.5)$ & $44(39.6)$ & $36(29.5)$ & $0.04^{*}$ \\
\hline & Non-drinking & 207 & $62(52.1)$ & $62(55.9)$ & $83(68.0)$ & \\
\hline \multirow[t]{2}{*}{ Smoking habits } & Smoking & 83 & $32(26.9)$ & $25(22.5)$ & $26(21.3)$ & 0.52 \\
\hline & Non-smoking & 245 & $78(65.5)$ & 79 (71.2) & $88(72.1)$ & \\
\hline \multirow[t]{2}{*}{ CES-D } & $<16$ & 253 & 84 (70.6) & 88 (79.3) & $81(66.4)$ & 0.09 \\
\hline & $\geqq 16$ & 99 & 35 (29.4) & $23(20.7)$ & 41 (33.6) & \\
\hline
\end{tabular}


Table 6 Demographics of non-health-conscious walkers (Continued)

\begin{tabular}{|c|c|c|c|c|c|c|}
\hline & & $\begin{array}{l}\text { Number of participants } \\
\text { in each demographic } \\
\text { category }\end{array}$ & $\begin{array}{l}\text { Number (\%) of } \\
\text { participants } \\
\text { walking } \geq 60 \\
\text { min/day }\end{array}$ & $\begin{array}{l}\text { Number (\%) of } \\
\text { participants walking } \\
\text { between } 30 \text { and } \\
60 \mathrm{~min} / \text { day }\end{array}$ & $\begin{array}{l}\text { Number (\%) of } \\
\text { participants } \\
\text { walking }<30 \\
\text { min/day }\end{array}$ & $p$ value \\
\hline \multirow[t]{2}{*}{ K6 } & $<9$ & 302 & $100(84.0)$ & $100(90.1)$ & 102 (83.6) & 0.29 \\
\hline & $\geqq 9$ & 50 & 19 (16.0) & $11(9.9)$ & $20(16.4)$ & \\
\hline \multirow[t]{2}{*}{ IES-R } & $<25$ & 282 & 95 (79.8) & $97(87.4)$ & 90 (73.8) & $0.03^{*}$ \\
\hline & $\geqq 25$ & 70 & $24(20.2)$ & $14(12.6)$ & $32(26.2)$ & \\
\hline
\end{tabular}

Distribution of walker without health-consciousness group regarding age groups (20-29, 30-39, 40-49, 50-59, 60-69, $\geqq 70)$, gender, number of family members, residential status at the time of the survey [living in the same place as before the Great East Japan Earthquake (GEJE), living in a different place with reasons other than the consequence of the GEJE, post-disaster publicly funded rental accommodation, houses of relatives or friends, prefabricated post-disaster public housing, newly built houses in the relocated high-land area, newly built houses outside of the relocated high-land area, others], economic states (extremely difficult, difficult, a little difficult, fine), alcohol consumption (drinking, non-drinking), smoking status (smoking, non-smoking), the Center for Epidemiologic Studies Depression Scale (CES-D; non-depressive: $<16$, depressive: $\geq 16$ ), the Kessler Psychological Distress Scale (K6; non-distressed: < 9, distressed: $\geq 9$ ), and the Impact of Event Scale-Revised (IES-R; non-PTSR $<25$, PTSR $\geqq 25$ ). The distributions of the above parameters were shown for each walking durations subgroup ( $\geqq 60$ min/ day, between 30 and $60 \mathrm{~min} /$ day, $<30 \mathrm{~min} /$ day). Differences in the distributions of each parameter among the three walking duration subgroups were evaluated using the Chi-square test

Significant levels: ${ }^{*} p<0.05,{ }^{* *} p<0.01$

Table 7 The results of ANCOVA to assess the influence of walking durations and covariate factors on the mental health indicators among non-health-conscious walkers

\begin{tabular}{|c|c|c|c|c|}
\hline Factor & $\begin{array}{l}\text { Sum } \\
\text { Sq }\end{array}$ & Df & $\begin{array}{l}F \\
\text { value }\end{array}$ & $\operatorname{Pr}(>F)$ \\
\hline \multicolumn{5}{|l|}{ CES-D } \\
\hline Age & 705 & 5 & 2.04 & 0.07 \\
\hline Gender & 132 & 1 & 1.91 & 0.17 \\
\hline Alcohol drinking habits & 75 & 1 & 1.093 & 0.3 \\
\hline Walking durations & 337 & 2 & 2.44 & 0.09 \\
\hline (interaction) Age:gender & 950 & 5 & 2.75 & $0.02^{*}$ \\
\hline Alcohol drinking habits:gender & 398 & 1 & 5.77 & $0.02^{*}$ \\
\hline Age:alcohol drinking habits:gender & 1112 & 5 & 3.22 & $0.008^{* *}$ \\
\hline Age:gender:walking durations & 2112 & 9 & 3.40 & $\begin{array}{l}< \\
0.001^{* * *}\end{array}$ \\
\hline \multicolumn{5}{|l|}{ K6 } \\
\hline Age & 78 & 5 & 0.82 & 0.53 \\
\hline Gender & 13 & 1 & 0.70 & 0.4 \\
\hline Alcohol drinking habits & 6 & 1 & 0.30 & 0.59 \\
\hline Walking durations & 75 & 2 & 1.99 & 0.14 \\
\hline $\begin{array}{l}\text { (interaction) Age:gender:walking } \\
\text { durations }\end{array}$ & 662 & 9 & 3.91 & $\begin{array}{l}< \\
0.001^{* * *}\end{array}$ \\
\hline \multicolumn{5}{|l|}{ IES-R } \\
\hline Age & 1304 & 5 & 1.32 & 0.26 \\
\hline Gender & 395 & 1 & 2.00 & 0.16 \\
\hline Alcohol drinking habits & 781 & 1 & 3.95 & $0.047^{*}$ \\
\hline Walking durations & 1170 & 2 & 2.96 & 0.054 \\
\hline (interaction) Age:gender & 4534 & 5 & 4.59 & $\begin{array}{l}< \\
0.001^{* * *}\end{array}$ \\
\hline
\end{tabular}

The table shows the results of the analyses of covariance (ANCOVA) to assess the influence of walking durations, as well as age, gender, and alcohol drinking habits as covariate factors, on the mental health indicators: the Center for Epidemiologic Studies Depression Scale (CES-D), the Kessler Psychological Distress Scale (K6), and the Impact of Event Scale-Revised (IES-R) among non-health-conscious walkers Sum Sq sum of squares, Df degrees of freedom, $\operatorname{Pr}$ probability Significance levels: ${ }^{*} p<0.05,{ }^{* *} p<0.01,{ }^{* * *} p<0.001$ esteem. While it was not certain that the belief in the positive effects of exercise positively affected physical health outcomes, the study suggested that the belief in the positive effects of exercise may improve mental health outcomes along with the physical health outcomes.

Table 8 The results of ANCOVA to assess the influence of walking durations and covariate factors on the IES-R subdomain indicators among non-health-conscious walkers

\begin{tabular}{lllll}
\hline Factor & Sum Sq & Df & $F$ value & $\operatorname{Pr}(>F)$ \\
\hline Re-experiencing & 224 & 5 & 1.63 & 0.15 \\
$\quad$ Age & 66 & 1 & 2.39 & 0.12 \\
Gender & 107 & 1 & 3.88 & $0.049^{*}$ \\
Alcohol drinking habits & 119 & 2 & 2.16 & 0.12 \\
Walking durations & 614 & 5 & 4.46 & $<0.001^{* * *}$ \\
(interaction) Age:gender & & & &
\end{tabular}

Avoidance

Age

Gender

Alcohol drinking habits

Walking durations

(interaction) Age:gender

$264 \quad 5 \quad 1.80$

0.11

$\begin{array}{llll}45 & 1 & 1.54 & 0.22\end{array}$

Hyperarousal

Age

Gender

Alcohol drinking habits

Walking durations

(interaction) Age:gender

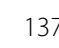

251

$0.03 *$

14.65

$0.01^{*}$

$463 \quad 5 \quad 3.15 \quad 0.009^{* *}$

Age:gender:walking durations

$\begin{array}{llll}48 & 5 & 0.53 & 0.75 \\ 26 & 1 & 1.41 & 0.24 \\ 35 & 1 & 1.94 & 0.17 \\ 77 & 2 & 2.14 & 0.12 \\ 474 & 5 & 5.24 & <0.001^{* * *} \\ 357 & 9 & 2.19 & 0.02^{*}\end{array}$

The table shows the results of the analyses of covariance (ANCOVA) to assess the influence of walking durations, as well as age, gender, and alcohol drinking habits as covariate factors, on the Impact of Event Scale-Revised (IESR) subdomain indicators: re-experiencing, avoidance, and hyperarousal among non-health-conscious walkers

Sum Sq sum of squares, Df degrees of freedom, $\operatorname{Pr}$ probability

Significance levels: ${ }^{*} p<0.05,{ }^{* *} p<0.01,{ }^{* * *} p<0.001$ 
Table 9 The results of ANCOVA to assess the influence of walking durations and covariate factors on the indicator of emotional pain among total participants

\begin{tabular}{lllll}
\hline Factor & Sum Sq & Df & $F$ value & $\operatorname{Pr}(>F)$ \\
\hline Emotional pain & & & & \\
Age & 15.97 & 5 & 3.49 & $0.004^{* *}$ \\
Gender & 0.49 & 1 & 0.54 & 0.46 \\
Alcohol drinking habits & 0.48 & 1 & 0.53 & 0.47 \\
Walking durations & 1.65 & 2 & 0.90 & 0.41 \\
\hline
\end{tabular}

The table shows the results of the analyses of covariance (ANCOVA) to assess the influence of walking durations, as well as age, gender, and alcohol drinking habits as covariate factors, on the indicator of feeling emotional pain by seeing signs related to a disaster or the landscape of the sea (emotional pain) among total participants

Sum Sq sum of squares, Df degrees of freedom, Pr probability Significance level: ${ }^{* *} p<0.01$

Thus, our results suggest that altering one's mindset to believe in the positive health outcomes of exercise, similar to the placebo effect seen in past research, may be associated with improved mental health. However, caution is needed because our study is a cross-sectional study. Instead of manipulating the motivation or mindsets of our participants, we have only examined the associations between the intention behind walking and their mental health and well-being. In previous studies, motivation and optimism were negatively associated with mental health conditions in general [28-30] and PTSR in communities affected by a disaster [40-42]. Our data might reflect less motivation and optimism in maintaining good health, probably due to poor mental health conditions.

Previous studies have reported that increased physical activity can lead to reduced PTSD symptoms [43, 44], but our study provides initial data to suggest a relationship between PTSR symptoms and health consciousness, specifically during walking behaviors. When walking was done with the intention of maintaining good health, longer walking durations were not associated with PTSR, unlike its association with depressive symptoms. These results suggest that walking habits may affect the symptoms of depression and PTSR in different ways.

On the other hand, our study suggests that people who walk less than $30 \mathrm{~min} /$ day among non-healthconscious walkers might have been somehow influenced by avoidance symptoms. Participants with avoidance symptoms of PTSR may deliberately avoid going out to walk, ultimately worsening their general health conditions, including depressive symptoms.

Considering that there are many signs relevant to a disaster in the living environment of these participants, for example, signs of the inundated area of the GEJE or prior evacuation points, the hypothesis that emotional pain from seeing reminders of post-disaster environments is associated with less walking duration was tested. However, this hypothesis was ultimately not supported by the current study. It may be necessary to intervene with people affected by disasters to increase health-conscious physical activities; however, the effective solution may not be to eliminate environmental triggers.

There were several limitations to this study. First, this study was a cross-sectional study based on the questionnaire survey conducted 7 years after the GEJE; therefore, a causal relationship between walking habit and mental health condition was not determined. Second, more detailed assessments of the manner of walking, such as intensity and posture of walking, were not conducted, and information regarding exercises other than walking was not taken into consideration. The reproducibility of the findings, along with the above issues, needs to be examined further in future studies with independent populations.

\section{Conclusion}

The current study provides initial evidence to support a negative association between walking durations and depressive state, but not PTSR, only among individuals who walked with a health-conscious mindset. Walking durations were negatively associated with avoidance symptoms among non-health-conscious walkers in the community affected by the GEJE, indicating that the disaster may have had a long-lasting impact on walking habits. Emphasizing the health benefits of walking for individuals recovering from a disaster may be beneficial for improving the mental health conditions of affected individuals.

\section{Abbreviations}

GEJE: The Great East Japan Earthquake; PTSR: Posttraumatic stress reaction; K6: The Kessler Psychological Distress Scale K-6 items; CES-D: The Center for Epidemiologic Studies Depression Scale; IES-R: The Impact of Event ScaleRevised

\section{Acknowledgements}

We thank the government of Shichigahama town and the residents of the town who have supported and participated in the survey.

\section{Authors' Contributions}

YU, IT, and HT conceived the design of the study. YU and HT conducted a major part of data analyses, interpretations, and drafted the manuscript. HN and $\mathrm{HT}$ took a major role in the management of the survey. NN, TN, NT, AN, and MK contributed to the data analyses and interpretation of the result. TS, MS, MK, JO, AS, NH, and YS contributed to the management of the survey and interpretation of the data. AK, YK, MK, AH, and IT supervised the survey, data analyses, and interpretations. All authors read and agreed to submit the final draft.

\section{Funding}

This work was supported by the Reconstruction Agency, the Ministry of Education, Culture, Sports, Science and Technology (MEXT), and the Japan Agency for Medical Research and Development (AMED) through the Tohoku Medical Megabank Project, Ministry of Health, Labour and Welfare, Japan, through a Health Sciences Research Grant for Health Services [H24-KenkiShitei-002, H25-Kenki-Shitei-002 (Fukko)], and an Intramural Research Grant for Special Project Research from International Research Institute of Disaster Science, Tohoku University, Japan, and Core Research Cluster of Disaster Science, Tohoku University, Japan. 


\section{Availability of Data and Materials}

Detailed data are available for access upon request. In those cases, some of the information will be excluded from the raw data to protect personal information.

\section{Ethics Approval and Consent to Participate}

The research protocol was approved by the Ethics Committee of Tohoku University. The participants answered the questionnaires after providing informed consent.

\section{Consent for Publication}

Not applicable.

\section{Competing Interests}

The authors, Yusuke Utsumi, Harumi Nemoto, Naoki Nakaya, Tomohiro Nakamura, Naho Tsuchiya, Akira Narita, Mana Kogure, Tomomi Suzuki, Moe Seto, Mitsuaki Katayanagi, Junko Okuyama, Atsushi Sakuma, Nami Honda, Yumi Sugawara, Halley Kaye-Kauderer, Yuta Takahashi, Akemi Kayama, Yoshihisa Kakuto, Masahiro Kohzuki, Atsushi Hozawa, Ichiro Tsuji, and Hiroaki Tomita, declare no conflicts of interest associated with this manuscript.

\section{Author details}

'Department of Disaster Psychiatry, Graduate School of Medicine, Tohoku University, 2-1 Seiryo-Machi, Aoba-ku, Sendai 980-8573, Japan. ${ }^{2}$ Miyagi Psychiatric Center, Mubanchi, Tekurada, Natori 981-1231, Japan. ${ }^{3}$ Department of Disaster Psychiatry, International Research Institute of Disaster Science, Tohoku University, 2-1 Seiryo-Machi, Aoba-ku, Sendai 980-8573, Japan. ${ }^{4}$ Department of Preventive Medicine and Epidemiology, Tohoku Medical Megabank Organization, Tohoku University, 2-1 Seiryo-Machi, Aoba-ku, Sendai 980-8573, Japan. ${ }^{5}$ Department of Psychiatry, Tohoku University Hospital, 1-1 Seiryo-Machi, Aoba-ku, Sendai 980-8574, Japan. ${ }^{6}$ Department of Psychiatry, Graduate School of Medicine, Tohoku University, 2-1 Seiryo-Machi, Aoba-ku, Sendai 980-8575, Japan. ${ }^{7}$ Department of Public Health, Graduate School of Medicine, Tohoku University, 1-1 Seiryo-machi, Aoba-ku, Sendai 980-8574, Japan. ${ }^{8}$ Department of Medical Education, Icahn School of Medicine at Mount Sinai, 1 Gustave L. Levy PI, New York, NY 10029, USA. ${ }^{9}$ Department of Occupational Therapy, Tohoku Bunka Gakuen University, 6-45-1 Kunimi, Sendai 981-8551, Japan. ${ }^{10}$ Department of Internal Medicine and Rehabilitation Science, Graduate School of Medicine, Tohoku University, 2-1 Seiryo-Machi, Aoba-ku, Sendai 980-8575, Japan.

\section{Received: 18 May 2019 Accepted: 3 July 2020}

\section{Published online: 16 July 2020}

\section{References}

1. Nakaya N, Nakamura T, Tsuchiya N, Narita A, Tsuji I, Hozawa A, Tomita H. Prospect of future housing and risk of psychological distress at 1 year after an earthquake disaster. Psychiatry Clin Neurosci. 2016;70:182-9. https://doi. org/10.1111/pen.12377.

2. Nakaya N, Nakamura T, Tsuchiya N, Narita A, Tsuji I, Hozawa A, Tomita H. Psychological distress and the risk of withdrawing from hypertension treatment after an earthquake disaster. Disaster Med Public Health Prep. 2017;11:179-82. https://doi.org/10.1017/dmp.2016.102.

3. Nakaya N, Narita A, Tsuchiya N, Nakamura T, Tsuji I, Hozawa A, Tomita H. Partners' ongoing treatment for chronic disease and the risk of psychological distress after the Great East Japan Earthquake. Tohoku J Exp Med. 2016;239:307-14. https://doi.org/10.1620/tjem.239.307.

4. Nakaya N, Nakamura T, Tsuchiya N, Tsuji I, Hozawa A, Tomita H. Unemployment risk among individuals undergoing medical treatment for chronic diseases. Occup Med (Lond). 2016;66:143-9. https://doi.org/10.1093/ occmed/kqv159.

5. Tsuchiya N, Nakaya N, Nakamura T. Narita A1, Kogure M, Aida J, Tsuji I, Hozawa A, Tomita H Impact of social capital on psychological distress and interaction with house destruction and displacement after the Great East Japan Earthquake of 2011. Psychiatry Clin Neurosci. 2017;71:52-60. https:// doi.org/10.1111/pen.12467.

6. Nakaya N, Nakamura T, Tsuchiya N, Tsuji I, Hozawa A, Tomita H. The association between medical treatment of physical diseases and psychological distress after the Great East Japan Earthquake: the Shichigahama Health Promotion Project. Disaster Med Public Health Prep. 2015;9:374-81. https://doi.org/10.1017/dmp.2015.52.
7. Mason P, Kearns A. Physical activity and mental wellbeing in deprived neighbourhoods. Mental Health and Physical Activity. 2013;6:111-7. https:// doi.org/10.1016/j.mhpa.2013.06.005.

8. Bize R, Johnson JA, Plotnikoff RC. Physical activity level and health-related quality of life in the general adult population: a systematic review. Preventive Medicine. 2007;45:401-15. https://doi.org/10.1016/j.ypmed.2007. 07.017.

9. Cerin E, Leslie E, Sugiyama T, Owenc N. Associations of multiple physical activity domains with mental well-being. Mental Health and Physical Activity. 2009;2:55-64. https://doi.org/10.1016/j.mhpa.2009.09.004.

10. Lok N, Lok S, Canbaz M. The effect of physical activity on depressive symptoms and quality of life among elderly nursing home residents: randomized controlled trial. Archives of Gerontology and Geriatrics. 2017;70: 92-8. https://doi.org/10.1016/j.archger.2017.01.008.

11. Kekäläinen T, Kokko K, Sipilä S, Walker S. Effects of a 9-month resistance training intervention on quality of life, sense of coherence, and depressive symptoms in older adults: randomized controlled trial. Qual Life Res. 2018; 27:455-65. https://doi.org/10.1007/s11136-017-1733-z.

12. Oeland A-M, Laessoe U, Olesen AV, Munk JP. Impact of exercise on patients with depression and anxiety. Nord J Psychiatry. 2010;64:210-7. https://doi. org/10.3109/08039480903511373.

13. Dunn AL, Trivedi MH, Kampert JB, Clark CG, Chambliss HO. Exercise treatment for depression: efficacy and dose response. Am J Prey Med. 2005. 28:1-8. https://doi.org/10.1016/j.amepre.2004.09.003.

14. Doyne EJ, Ossip-Klein DJ, Bowman ED, Osborn KM, Dougall-Wilson IB, Neimeyer RA. Running versus weight lifting in the treatment of depression. J Consult Clin Psychol. 1987;55:748-54. https://doi.org/10.1037//0022-006x. 55.5.748.

15. Martinsen EW, Hoffart A, Solberg O. Comparing aerobic with nonaerobic forms of exercise in the treatment of clinical depression: a randomized trial. Comprehensive Psychiatry. 1989;30:324-31. https://doi.org/10.1016/0010440x(89)90057-6.

16. White RL, Babic MJ, Parker PD, Lubans DR, Astell-Burt T. Lonsdale C Domainspecific physical activity and mental health: a meta-analysis. Am J Prev Med. 2017;52:653-66. https://doi.org/10.1016/j.amepre.2016.12.008.

17. Orstad SL, McDonough MH, Klenosky DB, Mattson M, Troped PJ. Neighborhood walkability and physical activity among older women: tests of mediation by environmental perceptions and moderation by depressive symptoms. Preventive Medicine. 2018;116:60-7. https://doi.org/10.1016/j. ypmed.2018.08.008.

18. Min KB, Kim HJ. Kim HJ1, Min JY. Parks and green areas and the risk for depression and suicidal indicators. Int J Public Health. 2017;62:647-56. https://doi.org/10.1007/s00038-017-0958-5.

19. Orstad SL, McDonough MH, James P, Klenosky DB, Laden F, Mattson M, Troped PJ. Neighborhood walkability and physical activity among older women: tests of mediation by perceptions and moderation by depressive symptoms. Preventive Medicine. 2018;116:60-7. https://doi.org/10.1016/j. ypmed.2018.08.008.

20. Charlotte $M$, et al. Physical activity and depression in young adults. Am J Prev Med. 2009;36:161-4. https://doi.org/10.1016/j.amepre.2008.09.036.

21. Jonsdottir $\mathbb{H}$, Rodjer L, Hadzibajramovic E, Borjesson M, Ahlborg G Jr. A prospective study of leisure-time physical activity and mental health in Swedish health care workers and social insurance officers. Preventive Medicine. 2010;51:373-7. https://doi.org/10.1016/j.ypmed.2010.07.019.

22. Smith TL, Masaki KH, Fong K, Abbott RD, Ross GW, Petrovitch H, Blanchette $\mathrm{PL}$, White LR. Effect of walking distance on 8-year incident depressive symptoms in elderly men with and without chronic disease: the HonoluluAsia Aging Study. J Am Geriatr Soc. 2010;58:1447-52. https://doi.org/10. 1111/j.1532-5415.2010.02981.X.

23. Tsuji T, Sasaki Y, Matsuyama Y, Sato Y. Aida J2, Kondo K. Kawachi I. Reducing depressive symptoms after the Great East Japan Earthquake in older survivors through group exercise participation and regular walking: a prospective observational study. BMJ Open. 2017;7:e013706. https://doi.org/ 10.1136/bmjopen-2016-013706.

24. Nakaya N1, Kogure M, Saito-Nakaya K, Tomata Y, Sone T, Kakizaki M, Tsuji I. The association between self-reported history of physical diseases and psychological distress in a community-dwelling Japanese population: the Ohsaki Cohort 2006 Study. Eur. J. Public Health. 2014;24:45-9. https://doi. org/10.1093/eurpub/ckt017.

25. Rosenbaum S, Vancampfort D, Steel Z, Newby J, Ward PB, Stubbs B. (2015). Physical activity in the treatment of post-traumatic stress disorder: a 
systematic review and meta-analysis. Psychiatry research. 2015;15(230):1306. https://doi.org/10.1016/j.psychres.2015.10.017.

26. American Psychiatric Association, editor. Diagnostic and statistical manual of mental disorders 5th ed. American Psychiatric Association, Washington, DC: American Psychiatric Association; 2013. https://doi.org/10.1176/appi.books. 9780890425596.

27. Black SV, Cooper R, Martin KR, Brage S, Kuh D, Stafford M. Physical activity and mental well-being in a cohort aged 60-64 years. Am J Prev Med. 2015; 49:172-80. https://doi.org/10.1016/j.amepre.2015.03.009.

28. Soundy A, Stubbs B, Probst M, Hemmings L, Vancampfort D. Barriers to and facilitators of physical activity among persons with schizophrenia: a survey of physical therapists Psychiatr. Psychiatric Serv. 2014;65:693-6. https://doi. org/10.1176/appi.ps.201300276.

29. Scarapicchia TM, Sabiston CM, O'Loughlin E, Brunet J, Chaiton M, O'Loughlin JL. Physical activity motivation mediates the association between depression symptoms and moderate-to-vigorous physical activity. Prev Med. 2014:66:45-8. https://doi.org/10.1016/j.ypmed.2014.05.017.

30. McDonald DD, Shellman JM, Graham L, Harrison L. The relationship between reminiscence functions, optimism, depressive symptoms, physical activity, and pain in older adults. Res Gerontol Nurs. 2016;9:223-31. https:// doi.org/10.3928/19404921-20160531-01

31. Kessler RC, Barker PR, Colpe L, Epstein JF, Gfroerer JC, Hiripi E, Howes MJ, Normand SL, Manderscheid RW, Walters EE, Zaslavsky AM. Screening for serious mental illness in the general population. Arch Gen Psychiatry. 2003; 60:184-9. https://doi.org/10.1001/archpsyc.60.2.184.

32. Furukawa TA, Kessler RC, Slade T, Andrews G. The performance of the K6 and K10 screening scales for psychological distress in the Australian National Survey of Mental Health and Well-Being. Psychol. Med. 2003;33: 357-62. https://doi.org/10.1017/s0033291702006700.

33. Furukawa TA, Kawakami N, Saitoh M, Ono Y, Nakane Y, Nakamura Y, Tachimori H, Iwata N, Uda H, Nakane H, Watanabe M, Naganuma Y, Hata Y, Kobayashi M, Miyake Y, Takeshima T, Kikkawa T. The performance of the Japanese version of the K6 and K10 in the World Mental Health Survey Japan. Int J Methods Psychiatr Res. 2008;17:152-8. https://doi.org/10.1002/ mpr.257.

34. Sakurai K, Nishi A, Kondo K, Yanagida K, Kawakami N. Screening performance of $\mathrm{K} 6 / \mathrm{K} 10$ and other screening instruments for mood and anxiety disorders in Japan. Psychiatry Clin Neurosci. 2011;65:434-41. https:// doi.org/10.1111/j.1440-1819.2011.02236.x.

35. Cho MJ, Nam JJ, Suh GH. Prevalence of symptoms of depression in a nationwide sample of Korean adults. Psychiatry Research. 1998;81:341-52. https://doi.org/10.1016/s0165-1781(98)00122-x.

36. Asukai N, Kato H, Kawamura N, Kim Y, Yamamoto K, Kishimoto J, Miyake Y, Nishizono-Maher A. Reliability and validity of the Japanese-language version of the impact of event scale-revised (IES-R-J): four studies of different traumatic events. J. Nerv. Ment. Dis. 2002;190:175-82. https://doi.org/10. 1097/00005053-200203000-00006.

37. Kanda Y. Investigation of the freely available easy-to-use software 'EZR' for medical statistics. Bone Marrow Transplantation. 2013;48:452-8. https://doi. org/10.1038/bmt.2012.244

38. Crum AJ, Langer EJ. Mind-set matters: exercise and the placebo effect. Psychol Sci. 2007;18:165-71. https:/doi.org/10.1111/j.1467-9280.2007.01867.x.

39. Arbinaga F, Fernández-Ozcorta E, Sáenz-López P, Carmona J. The psychological effects of physical exercise: a controlled study of the placebo effect. Scand J Psychol. 2018;59:644-52. https://doi.org/10.1111/sjop.12482.

40. Zhou B, Gu L, Ding Y, Shao L, Wu Z, Yang X. Li Changzhu. The great 2008 Chinese ice storm: its socioeconomic-ecological impact and sustainability lessons learned. Bulletin of the American Meteorological Society. 2011;92: 47-60. https://doi.org/10.1175/2010BAMS2857.1.

41. van der Velden PG, Kleber RJ, Fournier M, Grievink L, Drogendijk A, Gersons BP. The association between dispositional optimism and mental health problems among disaster victims and a comparison group: a prospective study. J Affect Disord. 2007;102:35-45. https://doi.org/10.1016/j.jad.2006.12. 004

42. Carbone EG, Echols ET. Effects of optimism on recovery and mental health after a tornado outbreak. Psychol Health. 2017;32:530-48. https://doi.org/10. 1080/08870446.2017.1283039.

43. Vancampfort D, Stubbs B, Richards J, Ward PB, Firth J, Schuch FB, Rosenbaum S. Physical fitness in people with posttraumatic stress disorder: a systematic review. Disabil Rehabil. 2017;39:2461-7. https://doi.org/10.1080/ 09638288.2016.1226412.
44. Vancampfort D, Richards J, Stubbs B, Akello G, Gbiri CA, Ward PB, Rosenbaum S. Physical activity in people with posttraumatic stress disorder: a systematic review of correlates. J Phys Act Health. 2016;13:910-8. https:// doi.org/10.1123/jpah.2015-0436

\section{Publisher's Note}

Springer Nature remains neutral with regard to jurisdictional claims in published maps and institutional affiliations.

\section{Submit your manuscript to a SpringerOpen ${ }^{\circ}$ journal and benefit from:}

- Convenient online submission

- Rigorous peer review

- Open access: articles freely available online

High visibility within the field

- Retaining the copyright to your article

Submit your next manuscript at $\boldsymbol{\nabla}$ springeropen.com 